\title{
Common Misconceptions and Future Intention to Smoke among Secondary School Students in Malaysia
}

\author{
Brinnell Caszo ${ }^{1 *}$, Muhammad Khair ${ }^{2}$, Mohd Habbib Mustafa ${ }^{2}$, Siti Nor Zafran², \\ Nur Syazmin², Raja Nor Intan Safinaz ${ }^{2}$, Justin Gnanou ${ }^{1}$
}

\begin{abstract}
Background: The prevalence of smoking among secondary school children continues to remain unchanged over the last 3 decades even though awareness regarding the health effects of smoking is increasing. Common misconceptions about smoking and parental influence could be factors influencing future intentions to smoke among these students. Hence, we looked at the common misconceptions as well as student perceptions about their future intention to smoke among Form 4 students in Shah Alam, Malaysia. Materials and Methods: This study was conducted by distribution of a questionnaire developed as part of the Global Youth Tobacco Survey to Form 4 student in 3 schools at Shah Alam. Results: Prevalence of smoking (current smokers) was 7.5\% . Almost half of the children came from families where one or both parents smoked and a third of the parents had no discussion regarding consequences of smoking with them. A large number of students were classified as "triers" as they had tried smoking and were unsure of whether they would not be smoking in the future. Contrary to our expectations, students generally felt smoking did make one feel more uncomfortable and helped one to reduce body weight. Most students seemed to be aware of the ill-effects of smoking on health. They felt they had received adequate information from school regarding the effects on smoking on health. Conclusions: Our study showed that even though Form 4 students in Shah Alam were knowledgeable about ill-effects of smoking and were taught so as part of their school curriculum, the prevalence of smoking was still high. Students in the "trier group" represent a potential group of future smokers and strategies targeting tobacco control may be aimed at tackling these vulnerable individuals. Efforts are also needed to help educate secondary school children about common misconceptions and dispel myths associated with cigarette smoking.
\end{abstract}

Keywords: Prevalence - smoking - secondary school students - tobacco control - "triers"

Asian Pac J Cancer Prev, 16 (3), 1159-1164

\section{Introduction}

It is disheartening to note that there has been little change in the prevalence of smoking among secondary school children in Malaysia over the past three decades. A study done on secondary school children in Kuala Lumpur in 1984, revealed a prevalence of $9.8 \%$ (Thambypillai, 1985). In a similar study done in 2008 , almost two decades later, schools in Petaling Jaya (a district near Kuala Lumpur) recorded the prevalence of smoking as 10\% (Lim et al., 2010). Though the prevalence did not decrease, it is encouraging to note that it did not increase among the secondary school children. Studies on school children have also been carried out in other parts of Malaysia. Shamsuddin and Haris (2000) reported, the prevalence of smoking among male students was $33.2 \%$ in a study done in Kota Bharu City, in the north eastern state of Kelantan in Malaysia. In 2005 in the southern Malaysian state of Johor smoking prevalence was $29.7 \%$, with prevalence among male students alone at more than $50 \%$ (Lim et al., 2006). The prevalence of smoking among students in a secondary school in Negri Sembilan was 14\% (Lee et al., 2005). Though the prevalence of smoking differs from region to region, in all studies quoted, the mean age at which participants started smoking is between $13-15$ years of age. This trend has been seen for the past three decades and it continues despite increasing awareness about the association between tobacco smoking and lung cancer, persuasive advertisement campaigns against smoking specifically targeting adolescent smokers (Aubin et al., 2012; Falcone etal., 2013) and inclusion of education about tobacco ill-effects in the school curriculum (Shukry et al., 2013).

There are many factors that might contribute to the failure of a tobacco prevention strategy. Influence of parents and peers who smoke maybe a significant and consistent predictor of adolescent smoking (Jo et al., 2011). The role of parents in adolescent smoking may 
be culture specific (Mahabee-Gittens et al., 2012) and in the Malaysian context, studies have shown that it plays a role in the initiation of smoking in adolescents (Nyi et al., 2004). Friendship with peers who smoke is not only associated with initiation but also with progression of smoking in adolescents. In a cross-sectional study done in 16 year old secondary school students in Johor district, Malaysia, it was found that smoking initiation and progression was associated with having either a brother or friend who smokes (Lee et al., 2005).

Common myths and misconceptions among adolescents regarding smoking are the second important factor that contributes to increased prevalence of smoking (Thomas and Drew, 2005). Adolescent smokers associate tobacco smoking to a symbol of personal freedom (Ho et al 2004). Other common myths and misconceptions among students are that smoking helps one to relax and makes one comfortable and that smoking helps reduce body weight or that quitting smoking would cause weight gain (Aubin et al., 2012). Some of these myths and misconceptions arise due to a misunderstanding of what seems to be common sense, while others might be due to the deliberate propagation of false information by the tobacco industry. The classic case being the introduction of 'light' or 'slim' cigarettes, which propagate the idea of loosing body weight after using these cigarettes especially among female students (Hammond et al, 2011).

In this study we assess the prevalence rate of smoking among urban Form 4 secondary school students from the city of Shah Alam, Selangor state, Malaysia. We also examine the role of parents and friends in the initiation of smoking, the students' opinion on the common myths and misconceptions about smoking and look at the students' outlook on future intentions to smoke.

\section{Materials and Methods}

The sample study population consisted of school children from three schools, selected at random in the city of Shah Alam, Selangor, Malaysia. All students participating in the study belonged to the Form 4 class of the academic year. A total of 642 students participated in this study, with $96 \%$ of the participants returning questionnaires considered valid for the purpose of this study. All students who participated were of Malay ethnicity. The study was of a cross-sectional questionnairebased design. A questionnaire based on the Global Youth Tobacco Survey (GYTS) by CDC, USA (Center for Disease Control and Prevention, 2009) was used. The questionnaire consisted of 21 questions with different options for the students to choose the most appropriate response. It dealt with students smoking experience, misconceptions about smoking, future intentions to smoke, knowledge about ill-effects of smoking as well as their perception of relationship between smoking with friendship and attractiveness. The questionnaire also evaluated the role of school and curriculum in imparting knowledge about smoking and its impact on health. Prior to the start of the study, permission was obtained from Ministry of Education Malaysia and Jabatan Pelajaran Selangor. After prior appointment with the school management and the teacher responsible, a thorough briefing was conducted to the students of the Form 4 section. They were informed of the process of the administration of the questionnaire and the study outcome. Informed consent was obtained from the students. The students took on an average of 45 minutes to answer the questionnaire. Students were asked to drop completed questionnaires into a drop box, thus ensuring complete anonymity. This study was approved by the research and ethics committee of the Faculty of Medicine, Universiti Teknologi MARA (UiTM). Data from incomplete or illegible surveys were discarded. Comparisons between male and female students or between non smokers and smokers, and a multinomial regression analysis to identify the relationship between common misconceptions regarding smoking and future intention to smoke were performed using SPSS 21 software (SPSS; Chicago, IL). A p value $<0.05$ was accepted as statistically significant.

\section{Results}

Form 4 students between the ages of 13-14 years from three randomly selected schools participated in this study. A total of 614 school children [227 (45.1\%) male and 337 (54.9\%) female] returned completely filled in questionnaire. Here, we present the results of the questionnaire in five distinct sections: smoking status and experience, future intentions to smoke; misconceptions about smoking; smoking and its relationship with friendship/attractiveness; involvement of school and knowledge about smoking.

\section{Smoking experience/status}

The majority of students $(67 \%)$ in this sample population had never tried smoking. About $7.5 \%$ were actual smokers, while $4.1 \%$ were occasional smokers. Most of the smokers were males $(84.7 \%, \mathrm{p}<0.01)$. However, a sizeable number of students $(21.5 \%)$ were classified as 'triers' as they had tried smoking. Among the triers, $60.6 \%$ were boys and $39.4 \%$ were girls. Among "triers", $53.1 \%$ came from families where fathers smoked, which was similar to current smokers $(56.8 \%)$ and occasional smokers (64\%), while only $32.4 \%$ nonsmokers came from families where fathers smoked. In all other respects "triers" were the same as subjects from the current smokers or "occasional" smokers (Table 1). Almost $40 \%$ of the fathers were smokers and there were no significant gender or smoking status differences.

The questionnaire also looked at whether parents had any discussion about smoking with their children. Majority of the students $(69.1 \%)$ had some discussion about smoking with their parents. More female students $(57.5 \%)$ than male students said they had discussions with their parents and this difference was statistically significant $(\mathrm{p}<0.005)$. Prevalence of smoking among students who had discussed smoking with their parents was $6.4 \%$ $(n=27)$. On the other hand, among smokers, $58.7 \%$ had some kind of discussion with their parents.

Future intentions to smoke

Students were asked whether they would be tempted 
Table 1. Parental Influence

\begin{tabular}{|c|c|c|c|c|c|c|}
\hline & & \multicolumn{5}{|c|}{ Smoking status of parents } \\
\hline & & Father only $(\%)$ & Mother only (\%) & Both $(\%)$ & None $(\%)$ & $\mathrm{p}$ value \\
\hline Overall & & $242.3(39.4)$ & $3(0.5)$ & $10(1.6)$ & $351(57.2)$ & \\
\hline \multirow[t]{4}{*}{ Smoking status } & Non-smokers & $132 \quad(54.5)$ & $1(33.3)$ & $2(20)$ & $272(77.5)$ & \\
\hline & Trier & $69 \quad(28.5)$ & $1(33.3)$ & $2(20)$ & $58(16.5)$ & \\
\hline & Occasional smoker & $16 \quad(6.6)$ & $0(0)$ & $1(10)$ & $8(2.2)$ & \\
\hline & Smoker & $(10.3)$ & $1(33.3)$ & $5(50)$ & 13 (3.7) & $<0.00$ \\
\hline \multirow[t]{2}{*}{ Gender } & Male & 113 (41.2) & $3(1.1)$ & $5(1.8)$ & $153(55.8)$ & \\
\hline & Female & $129 \quad(38.9)$ & $0(0)$ & $5(1.5)$ & $198(59.6)$ & $>0.05$ \\
\hline
\end{tabular}

Table 2. Intention to Smoke

\begin{tabular}{|c|c|c|c|c|c|c|c|c|}
\hline & \multicolumn{4}{|c|}{ Intention at 12 months } & \multicolumn{4}{|c|}{ Intention after 5 years } \\
\hline & $\begin{array}{c}\text { Definitely } \\
\text { not }(\%)\end{array}$ & $\begin{array}{c}\text { Probably } \\
\text { not }(\%)\end{array}$ & $\begin{array}{c}\text { Probably } \\
\text { yes }(\%)\end{array}$ & $\begin{array}{c}\text { Definitely } \\
\text { yes }(\%)\end{array}$ & $\begin{array}{c}\text { Definitely } \\
\operatorname{not}(\%)\end{array}$ & $\begin{array}{c}\text { Probably } \\
\text { not }(\%)\end{array}$ & $\begin{array}{c}\text { Probably } \\
\text { yes }(\%)\end{array}$ & $\begin{array}{c}\text { Definitely } \\
\text { yes }(\%)\end{array}$ \\
\hline Overall & $469(76.6)$ & $71(11.6)$ & $51 \quad(8.3)$ & $21 \quad(3.4)$ & $441(71.8)$ & $92(15.0)$ & $66(10.7)$ & $15 \quad(2.4)$ \\
\hline \multicolumn{9}{|l|}{ Smoking status } \\
\hline Non-smokers & $380(92.7)$ & $25(6.1)$ & $4(1.0)$ & $1(0.2)$ & $361(87.8)$ & $38 \quad(9.2)$ & $12(2.9)$ & $0 \quad(0.0)$ \\
\hline Trier & $86(65.6)$ & $33(25.2)$ & $11 \quad(8.4)$ & $1(0.8)$ & $74(56.1)$ & $40(30.3)$ & $18(13.6)$ & $\begin{array}{ll}0 & (0.0)\end{array}$ \\
\hline Occasional smoker & $2(8.0)$ & $7(28.0)$ & $15(60.0)$ & $1(4.0)$ & $2(8.0)$ & $3(12.0)$ & $16(64.0)$ & $4(16.0)$ \\
\hline Smoker & $1 \quad(2.2)$ & $6(13.0)$ & $21(45.7)$ & $18(39.1)$ & $4(8.7)$ & $11(23.9)$ & $20(43.5)$ & $11(23.9)$ \\
\hline \multicolumn{9}{|l|}{ Gender } \\
\hline Male & $166(60.4)$ & $48(17.5)$ & $43(15.6)$ & $18 \quad(6.5)$ & $151(54.5)$ & $59(21.3)$ & $54(19.5)$ & 13 (4.7) \\
\hline Female & $303(89.9)$ & $23(6.8)$ & $9(2.4)$ & $3(0.9)$ & $290(86.1)$ & $33 \quad(9.8)$ & $12(3.6)$ & $2(0.6)$ \\
\hline
\end{tabular}

to smoke in the next 12 months and in the next 5 years given their present environment, friends, and knowledge about smoking. Majority of students (76.6\%) said they had no intention to smoke. The remaining $23.3 \%$ were not sure and out of these students, only $3.4 \%$ had a definite intention to smoke in the next 12 months. More interestingly, the data showed that among smokers, $39.1 \%$ $(n=18)$ were definitely sure they would be smoking in the next 12 months. Among female students, almost $90 \%$ were definitely sure they would not be smoking in the next 12 months; however among males only $60.4 \%$ were definitely sure, while the rest (39.4\%) could not take a definite stand. When asked regarding their intention to smoke 5 years from now a majority $(71.8 \%)$ said they had no intention. We observed that a larger percentage of students were not sure $(28.2 \%)$ compared to the number expressing their intention not to smoke in 12 months' time (Table 2).

The number of students who were not sure whether they would be smoking after 5 years' time fell, almost $72 \%$ were very sure they would never smoke even if their best friend offered them to smoke. While $92.7 \%$ of non-smokers were definitely sure they would not smoke in 12 months' time, only $65.6 \%$ of "triers" were definitely sure. Almost $34 \%$ of "triers" said they "probably would or probably would not" be sure about their future intention to smoke; only $7 \%$ of non-smokers were in this grey and indecisive opinion. When asked about their intention to smoke after 5 years, the $65.6 \%$ of "triers" who were sure of not smoking dropped to $56.1 \%$, while the indecisive group increased to $44 \%$ (Table 2).

\section{Misconceptions about smoking}

Our study also examined common misconceptions regarding smoking. When asked whether smoking made a person feel comfortable, only $15.8 \%$ felt smoking actually made someone feel more comfortable. Overall, most students $(56.7 \%)$ felt smoking actually made them less comfortable and there were no differences between responses of male and female students. Among female students, $63.6 \%$ felt smoking made one less comfortable when compared to male students and this difference was statistically significant $(\mathrm{p}<0.001)$. More male students $(48.4 \%)$ actually felt that smoking did not contribute to one feeling comfortable.

The other common misconception we examined was that smoking caused weight loss. In our study, $50 \%$ of the students expressed an opinion that smoking caused weight loss. Significantly more females felt that smoking caused weight loss $(\mathrm{p}<0.01)$. When asked if smoking was harmful to health, about $88 \%$ of the students agreed that smoking caused health problems. Only a small fraction of students $(3.7 \%)$ felt smoking did not cause health problems. There was a gender difference regarding this opinion, with significantly more female students $(93.8 \%$ vs $81.6 \%$ ) agreeing that smoking was harmful to health.

A multinomial regression analysis performed to study the effect of misconceptions on future intention to smoke revealed that feeling less comfortable while smoking negatively predicted a definite future intention to smoke both after 12 months (OR, 0.3, 95\% confidence interval (CI), 0.1-0.9) and 5 years (OR, 0.2, 95\%CI, 0.51.0). A misconception that smoking caused weight loss, negatively predicted behavior to abstain from smoking in future, after 12 months (OR, 0.5, 95\%CI, 0.3-0.9) and 5 years (OR, 0.5, 95\%CI, 0.3-0.8).

\section{Smoking and its relationship with friendship and attractiveness}

Smoking did not influence friendship among male smokers $(64.3 \%)$. Interestingly, $20.6 \%$ felt that smoking actually increased the chance of making more friends among male smokers. When asked about female smokers, about $60 \%$ felt that female smokers would have fewer friends. Only $5.7 \%$ felt they would have more friends. 
Again there was no gender difference in this opinion. Regarding attractiveness, $60 \%$ felt less attracted to boys who smoked and about $86 \%$ felt less attracted to female students who smoked.

\section{Smoking and involvement of school}

Students were asked whether they were taught about the dangers of smoking at school as well as whether they were taught about the health effects of tobacco smoking. Majority of students $(80.6 \%)$ answered that they were taught about the dangers of smoking at school and this opinion was uniform across genders. A similar response $(82 \%)$ was obtained regarding teaching about the health effects of smoking. However there was a gender specific difference for this opinion, significantly larger number of females reported that they had been taught about the health effects of smoking $(86.6 \%)$.

\section{Discussion}

In this study, the prevalence of smoking among Form 4 secondary school students was $11.6 \%$, which included both current and occasional smokers. This is a marginal increase in the prevalence rate when compared to a similar study done in 1984 on similar student group in which the prevalence rate was $9.8 \%$ (Thambypillai, 1985) and another study done in Petaling Jaya in the year 2008, among urban students of similar age (Form 4 students) with the prevalence rate at $10 \%$ (Lim et al., 2010). In contrast, smoking prevalence among university students in Malaysia was 29\% in a study done in 2009 (Al Naggar et al., 2011). However, some other studies done on Form 4 students in Malaysia estimated a much higher prevalence rate (Kota Bharu-33.2\%; Johor Bahru-29.7\%; Negri Sembilan-14\%; Hulu Langat-37\%) (Shamsuddin et al., 2000; Lim et al, 2004; Lee et al., 2006; Khairani O et al., 2007). This may be due to urban and rural differences, with studies based in rural areas showing a higher prevalence.

From our study we were also able to identify a group of students who fell in the category of "triers". These students have tried at least one puff of a cigarette. Of the "triers", $60 \%$ were males, $53.1 \%$ came from families where fathers smoked, while only $32.4 \%$ non-smokers came from families where fathers smoked and were similar to subjects from the "current" or "occasional smokers" in all other respects. The "triers" may be considered the most vulnerable group among the adolescent student population and it has been demonstrated that this group of students go through a period of dormant vulnerability which has been termed the "sleeper effect". This period of vulnerability to smoking can be as long as 3 years (Fidler et al, 2004). We observed a significant difference between triers and non-smokers regarding future intentions to smoke. Significantly more $(92.7 \%)$ of non-smokers were definitely sure they would not smoke in 12 months' time, compared to only $65.9 \%$ of "triers" were definitely sure. More (34\%) "triers" were unable to commit to their intention not to smoke in 12 months' time compared to non-smokers. Responses regarding intention to smoke after 5 years, fewer "triers" committed to not smoking more remained indecisive (44\%). This is a worrying trend among "triers" as it is well documented that even infrequent experimentation with cigarettes can increase the risk for smoking later on in life by a factor of 16 (Chassin et al., 1990).

The high prevalence of "triers" and their attitude towards a positive future intention to smoke shifting them from "sleeper" to active smoker may be attributed to the susceptibility of these adolescents to various myths and misconceptions about smoking. One of the most 'appealing' misconceptions misused or perpetuated by the tobacco industry is that smoking leads to alteration in body weight (both loss and gain). In a large cohort study as part of the Coronary Artery Risk Development in Young Adults study, which followed up participants for 7 years found that smoking only has minimal impact of body weight (Klesges et al, 1998). However this misconception still exists among the students. Studies also show that a desire to lose weight may be associated with smoking initiation (Cawley et al., 2004; Frieden and Blakeman, 2005). In our study, we found that $50 \%$ of all students associated smoking with weight loss and there was no difference in this opinion between the genders.

Smoking has also been associated with the feeling of relaxation and stress relief. However, evidence indicates otherwise. Stress levels of smokers are generally higher than non-smokers. Among adolescent smokers stress levels increased as they developed a regular smoking habit. The apparent relaxation effect of smoking is mainly attributed to the reversal of irritability that develops during nicotine dependency (Parrott and Murphy, 2012). This misconception is associated with many other similar beliefs such an increase in popularity among peers (Schaefer et al., 2012). These beliefs may be so strong as to act as motivation and induce adolescents to start smoking and ignore evidence that indicates its association with lung cancer, decreased exercise tolerance and breathlessness. In fact, the feeling of relaxation after smoking is a strong predictor of nicotine dependency (DiFranza et al., 2007). Thus our results indicate that students are unaware that cigarette smoking increases stress rather than decreases it and continue to believe otherwise, in spite of the information received from school as well as from their parents. Students who smoked tended to have parents who were smokers too, supporting evidence shown by other researchers (Odukoya et al., 2013). Parental behaviour appears to influence the decision to use tobacco much more than appears to be very much a determining factor. In addition, results of the multinomial logistic regression on this study population also point in a similar direction; students who had unfavourable misconceptions (feeling uncomfortable) regarding smoking were less likely to smoke in future, while those who felt smoking caused weight loss were less likely to abstain from smoking in future.

We asked students whether they received information regarding dangers of smoking and the health effects of smoking in school. It is a positive finding to note that most of the students agreed that they were taught in schools regarding dangers of smoking and the health effects of smoking. It has been recommended by the CDC that apart from including physical and social consequences of 
tobacco use in the school curriculum, decision-making, problem solving and refusal skills might also be included to help students resist peer pressure to start smoking (Center for Disease Control and Prevention, 2012); since the effect of having a friend smoke has been shown to be associated with early initiation (Muttappallymyalil et al., 2012). We would like to suggest that students should also be sensitized to the common myths and misconceptions regarding smoking in addition to the dangers of smoking and the health effects of smoking. Female students appeared to be better informed regarding the effects of smoking, and less likely to have an intention to smoke in the future. Similar findings were reported from data taken from Third National Health and Morbidity Survey (Cheah and Naidu, 2012). This is in contrast to data available regarding adults from Global Adult Tobacco Survey, (GATS), which show a trend of populations being well informed regarding the effects of smoking, but is not giving up the use of tobacco (Gupta and Kumar, 2014).

There are a few limitations to this study. Data for our study was obtained through a self-administered questionnaire. Responses were self-reported and of course depended on recall of the subjects and possibly deliberate misreporting-the recall bias. However self-reports may be considered reliable (Wong et al., 2012). We also ran no biochemical tests to verify smoking status such as measuring cotinine or exhaled carbon monoxide. The quantity and duration of smoking was not documented in this study, as our primary aim was to look at students perceptions regarding smokers and smoking, as has been shown in other. Our sample included only three schools from the region and thus our data may not be generalised to represent the entire population. In addition, though secondary school enrolment is $77 \%$ for boys and $81 \%$ for girls in Malaysia (UNICEF Malaysia Communications, 2008), our sample looked at only at school-going children and did not include those not enrolled in school. Lastly our questionnaire did not include information regarding personal characteristics; such as smoking behaviour and physique and body image, which might confound our results.

Despite these limitations, our study indicates that the identification of and strategies focussed on the group of students that fall into the "trier" category may be a novel and important factor towards achieving success with a tobacco campaign. The results of this study also support the formulation of interventions to prevent tobacco use in young adolescents (Dhavan et al., 2009). The existence of common misconceptions among students may also be a reason to motivate them to start smoking. Interventions designed to dispel these myths may be of help. Our findings thus provide a fresh insight to the problem of smoking among adolescents. School programs may reap more positive results if their efforts are aimed at the "trier" group of students and develop strategies specifically targeting them. An approach that involves parents, and creates an awareness of the potential impact their own choices make on that of their children's, might be a more fruitful one. Lastly, a proactive effort to clear the common misconceptions about smoking to students needs to be undertaken. These measures would definitely form a critical factor in reducing the prevalence of smoking among adolescents.

\section{Acknowledgements}

The authors would like to thank all the students who participated in this study.

\section{References}

Al-Naggar RA, Al-Dubai SA, Al-Naggar TH, Chen R, AlJashamy K (2011) Prevelance of smoking and associated factors among Malaysian University students. Asian Pac J Cancer Prev, 12, 619-24.

Aubin HJ, Farley A, Lycett D, Lahmek P, Aveyard P (2012). Weight gain in smokers after quitting cigarettes: metaanalysis. BMJ, 345, 4439 .

Cawley J, Markowitz S, Tauras J (2004). Lighting up and slimming down: the effects of body weight and cigarette prices on adolescent smoking initiation. $J$ Health Econ, 23, 293-311.

Chassin L, Presson CC, Sherman SJ, Edwards DA (1990). The natural history of cigarette smoking: Predicting young-adult smoking outcomes from adolescent smoking patterns. Health Psychol, 9, 701-16.

Cheah YK, Naidu BM (2012). Exploring factors influencing smoking behaviour in Malaysia. Asian Pac J Cancer Prev, 13, 1125-30.

Dhavan P, Stigler1 MH, Perry CL, Arora M, Reddy KS (2009). Patterns of tobacco use and psychosocial risk factors among students in 6th through 10th grades in India: 2004-2006. Asian Pac J Cancer Prev, 10, 807-81.

DiFranza JR, Savageau JA, Fletcher K, et al (2007). Susceptibility to nicotine dependence: the development and assessment of nicotine dependence in youth 2 study. Pediatrics, 120, 974-83.

Falcone M, Lerman C, Cappella JN, et al (2013). No untoward effects of smoking cues in anti-smoking public service announcements. Drug Alcohol Depend, 133, 279-82.

Fidler JA, Wardle J, Brodersen NH, et al (2006). Vulnerability to smoking after trying a single cigarette can lie dormant for three years or more. Tob Control, 15, 205-9.

Gupta B, Kumar N (2014). A Cross-country comparison of knowledge, attitudes and practices about tobacco use: findings from the global adult tobacco survey. Asian Pac J Cancer Prev, 15, 5035-42.

GYTS (2009). Core questionnaire. centers for disease control and prevention, GYTS.

Hammond D, Doxey J, Daniel S, Bansal-Travers M (2011). Impact of female-oriented cigarette packaging in the United States. Nicotine Tob Res, 13, 579-88.

Ho MG, Ma S, Chai W, et al (2010). Smoking among rural and urban young women in China. Tob Control, 19, 13-8.

Khairani O, Norazua R,Zaiton A (2007). Prevalence and Reasons for Smoking among Upper Secondary Schoolboys in Hulu Langat, Malaysia. Med Health, 2, 80-5.

Klesges RC, Ward KD, Ray JW, et al (1998). The prospective relationships between smoking and w eight in a young, biracial cohort: the coronary artery risk development in young adults study. J Consult Clin Psycho, 66, 987-93.

Latimer AE, Krishnan-Sarin S, Cavallo DA, et al (2012). Targeted smoking cessation messages for adolescents. $J$ Adolesc Health, 50, 47-53.

Lee LK, Paul CYC, Kam CW, Jagmohni K (2005). Smoking among secondary school students in Negri Sembilan, Malaysia. Asia Pac J Public Health, 17, 130-6. 
Leonardi-Bee J, Jere ML, Britton J (2011). Exposure to parental and sibling smoking and the risk of smoking uptake in childhood and adolescence: a systematic review and metaanalysis. Thorax, 66, 847-55.

Lim KH, Amal NM, Hanjeet K, et al (2006). Prevalence and factors related to smoking among secondary school students in Kota Tinggi District, Johor, Malaysia. Trop Biomed, 23, 75-84.

Lim KH, Sumarni MG, Kee CC, et al (2010). Prevalence and factors associated with smoking among form four students in Petaling District, Selangor, Malaysia. Trop Biomed, 27, 394-403.

Mahabee-Gittens EM, Xiao Y, Gordon JS, Khoury JC (2012). The role of family influences on adolescent smoking in different racial/ethnic groups. Nicotine Tob Res, 14, 264-73.

Muttappallymyalil J, Divakaran B, Thomas T, et al (2012). Prevalence of tobacco use among adolescents in India. Asian Pacific J Cancer Prev, 13, 5371-4.

Nyi NN, Zulkifli A, Razlan M, et al (2004). Factors related to smoking habits of male adolescents. Tob Induc Dis, 2 , 133-40.

Odukoya OO, Odeyemi KA, Oyeyemi AS, Upadhyay RP(2013). Determinants of smoking initiation and susceptibility to future smoking among school-going adolescents in Lagos State, Nigeria. Asian Pac J Cancer Prev, 14, 1747-53.

Parrott AC, Murphy RS (2012). Murphy. Explaining the stressinducing effects of nicotine to cigarette smokers. Hum Psychopharmacol Clin Exp, 27, 150-5.

Preventing tobacco use among youth and young adults: a report of the surgeon general, HHS, centers for disease control and prevention, national center for chronic disease prevention and health promotion, office on smoking and health, 2012.

Schaefer DR, Haas SA, Bishop NJ (2012). A dynamic model of US adolescents' smoking and friendship networks. Am J Public Health, 102, 12-8.

Shamsuddin K, Haris MA (2000). Family influence on current smoking habits among secondary school children in Kota Bharu, Kelantan. Singapore Med J, 41, 167-71.

Shukry Z, Maizurah O, Rahmat A, et al (2013). Effectiveness of antismoking media messages and education among adolescents in Malaysia and Thailand: findings from the international tobacco control southeast asia project. Nicotine Tob Res, 15, 482-91.

Frieden TR, Blakeman DE (2005). The dirty dozen: 12 Myths that undermine tobacco control. Am J Public Health, 95, 1500-5.

UNICEF Malaysia communications, 15 Aug 2008 a human rights based approach to education for all, UNICEF/UNESCO 2007, New York.

Thambypillai V (1985). Smoking among urban Malaysian school children. Soc Sci Med, 21, 819-23.

Wong SL, Shields M, Leatherdale S, Malaison E, Hammond D (2012). Assessment of validity of self-reported smoking status. Health Rep, 23, 47-53. 